\title{
CATALOGACIÓN DEL PATRIMONIO HISTÓRICO (Cuadernos. Instituto Andaluz del Patrimonio Histórico)
}

\begin{abstract}
La realización en éstos últimos años de varios cursos, congresos, jornadas, seminarios etc.. tratando el tema del PATRIMONIO HISTÓRICO podría llevarnos a empezar esta reseña diciendo que estamos asistiendo a un incremento importante del interés social por el Patrimonio histórico; no quisiera sin embargo engañarme, ni engañar a los posibles lectores/as con esa libre interpretación, pero lo que si es cierto es que el tema parece haber adquirido importancia en los últimos tiempos en determinados ámbitos, al menos en aquellos que están ligados de alguna forma a la protección conservación y difusión de ese Patrimonio.

Hay una frase sobradamente utilizada en todos los foros cuando se habla de Patrimonio: "no podemos proteger lo que no conocemos", o lo que es lo mismo, para proteger algo tenemos que conocer al menos la existencia de ese algo. De ahí la importancia de catalogar el Patrimonio Histórico.
\end{abstract}

Y es así como nos encontramos con esta obra, que responde a las I Jornadas sobre Catalogación del Patrimonio Histórico, organizadas por el Instituto Andaluz del Patrimonio Histórico. celebradas en Sevilla del 19 al 22 de abril de 1995.

Antes de empezar deberíamos ver que es lo que se entiende por Patrimonio Histórico. En las distintas comunicaciones que configuran este libro se pueden leer diversas definiciones de este término. Si tuviera que buscar una frase que las resumiera, esta podría ser la que oí en estas mismas Jornadas, una definición que hizo $M^{a}$ Angeles Querol en la mesa redonda, (tengo que decir a este respecto que lamento que las intervenciones de esta Mesa no se hayan publicado ya que resultaron de gran interés), definición que me parece de lo más acertada. Querol venía a decir que el Patrimonio Histórico para algunos se trata de un mundo muy pequeño y muy dividido, mientras que para otros es algo muy amplio relacionado siempre con el Patrimonio Natural colocado sobre el planeta, con lo que prácticamente todo es Patrimonio. Y es que como muy bien ella decía nos encontramos en un mundo en que los conceptos son tan móviles como el propio concepto de Patrimonio Histórico.

De ahí el interés de resaltar la pluridisciplinaridad con la que ha sido tratado el tema en estas Jornadas como veremos al desarrollar, aunque brevemente, el contenido de las mismas. También hay que resaltar su publicación, que hace que esté realizando ahora esta reseña, ya que es importante que reuniones como esta lleguen a ver la luz y no se queden contenidas en lo que durante unos días un grupo de especialistas y gentes interesadas en un tema debatieron contrastando sus trabajos y marcando nuevas líneas en las que seguir trabajando. El hecho de salir hacia fuera y mostrarse al público en general interesado en el tema, hace que se pueda reflexionar a partir de su lectura sobre toda una serie de conceptos, valores etc. que allí se barajaron. Desde esa perspectiva pluridisciplinar, como ya he señalado, se abren toda una serie de campos hasta hoy no tenidos en cuenta en los que se van a tratar desde contenidos científicos específicos hasta experiencias y proyectos.

La problemática de los catálogos y sus finalidades en la Política de los Bienes Culturales, va a ser el marco en el que se van a insertar las comunicaciones que aqui se presentan. Sin entrar en extensión en las políticas seguidas en materia de Patrimonio Histórico a lo largo del tiempo, si encontramos las lineas seguidas desde siglo XVIII, las normas que irán surgiendo a lo largo del XIX en materia de conservación, protección y regulación de la exportación que desembocaran en la creación de las primeras instrucciones para cumplimentar el Catálogo Monumental y Artístico de la Nación en 1900 y podemos seguir un breve recorrido por el s. $X X$ con la promulgación de la ley de 1933, hasta llegar a la Ley de Patrimonio Histórico de 1985. Sobre ésta última se analizarán más en profundidad algunos aspectos, entre ellos, su definición que pone de manifiesto como ya he señalado antes la enorme extensión del concepto de Patrimonio Históri$c o$, en el que hay que analizar la gran diversidad de bienes que se incorporan hasta la aparición del concepto de Bien de Interés Cultural.

Es interesante ver también como se han contrastado en algunos aspectos la legislación del Patrimonio Histórico del Estado con la Ley del Patrimonio Histórico de Andalucía, que crea ya un Catálogo General del P. H. Andaluz como instrumento para salvaguarda de los Bienes en él inscritos, consulta y divulgación del mismo, y que intenta ya una mayor armonización con los instrumentos de planeamiento, e irá ya acompañado de Planes para la protección de Conjuntos Históricos.

Podemos extraer una conclusión clara de la lectura de estos trabajos: hay que considerar el hecho de que el Bien o los Bienes no son algo aislado sino que tienen un contexto. No se trata pues de resaltar alguno de sus valores, puesto que los valores no solo están en el Bien en si sino también en lo que le rodea. Se pasa a valorar el medio que rodea al Bien, y para ello se irá desde la entidad mínima a la máxima: el territorio. Este es pues un punto importante a tener en cuenta, puesto que si entendemos el Bien como algo contextualizado y no como algo en sí mismo, entenderemos el porque de la necesidad de un trabajo interdisciplinar para la tutela de ese Bien, y por lo tanto para la gestión, conservación y difusión del Patrimonio Histórico.

Desde esa interdisciplinaridad se entiende también la aplicación sobre éste de nuevas metodologías, así como la creación por parte de la administración andaluza de un centro como es el Centro de Documentación del Patrimonio Histórico de Andalucía que pretende impulsar y coordinar la participación de las Instituciones públicas y 
privadas en un Proyecto común de documentación e información patrimonial, cuya labor también se expuso en estas Jornadas.

Hay que valorar la importancia de utilizar como instrumento las normas de planeamiento. El territorio, nuestra entidad máxima de trabajo, es el espacio desde el que hay que plantear también las estrategias para las políticas de patrimonio. Todo lo que es la ordenación del territorio y la planificación territorial, aunque puedan parecer muy alejadas del tema que aquí nos trae, estan por el contrario muy vinculadas aunque son muy poco tenidas en cuenta. La planificación territorial se convierte en una fuente de infomación para la toma de decisiones, por ello, aquellos y aquellas que trabajan en el tema deben tenerlo en cuenta.

Una rápida mirada hacia lo que se dice sobre el Patrimonio Histórico en el EDTC (Esquema de Desarrollo Territorio Comunitario) en el borrador de Leipzig 1994, nos presenta el desarrollo del Patrimonio como elemento dentro de la estrategia de desarrollo territorial sostenible. No vamos a ver aquí como se trata el tema del patrimonio en políticas territoriales europeas, ni las españolas allí donde se han aprobado Planes territoriales, pero si creemos oportuno hacer estas referencias para que a quienes esten interesados por el tema reflexionen sobre ello y lean esos documentos. Recientemente se han publicado las "Bases para una Carta sobre Patrimonio y Desarrollo en Andalucía", que se nos presentan como el resultado del trabajo de profesionales representantes de diversas áreas de la Administración autonómica coordinados por el Instituto Andaluz de Patrimonio Histórico, donde se va a valorar el Patrimonio como recurso, y donde el territorio como hemos señalado va a ser el espacio desde el que plantear las estrategias a seguir.

Por todo lo que estoy diciendo vemos que realmente las leyes que ahora manejamos sobre Patrimonio Histórico se nos han quedado cortas, ya que parecen repetir en algunos aspectos herencias del pasado y como decía hace muy poco una Jurista, Concha Barrero ', hablando sobre este tema, nuestras leyes, a este respecto, presentan una división interna muy poco consistente, que hace que muchos de los aspectos que estamos comentando y que se analizan en los trabajos que estamos tratando se escapen.

Tras las reflexiones aquí expuestas que han sido provocadas en esta lectora por la lectura de las ponencias aquí presentadas ${ }^{2}$ paso a ver como se articula la obra.

Es precisamente con una Reflexión sobre la Catalogación en el marco de los Bienes Culturales, de Roman Fernández-Baca Casares, director de este Instituto Andaluz del P.H. con la que se inicia, y lo hace de una manera genérica sobre todos estos aspectos que ya he señalado, un recorrido por las distintas leyes, donde se remarcan hechos significativos y es interesante el comentario sobre la ley del 85, donde señala como en esta ley se abordan por primera vez aspectos importantes que vinculan al Patrimonio con las políticas sectoriales, pudiéndose tratar temas de Patrimonio y urbanismo sin que estos estén reñidos, sobre todo utilizando como instrumento las normas de Planeamiento, a todos los niveles desde la administración local (ayuntamientos), hasta las administraciones regionales.

A partir de ese primer trabajo, se presentan un total de 18 artículos, en los que se encuentran los diferentes campos que abarca el Patrimonio Histórico: Patrimonio Arquitectónico, Arqueológico, Etnológico y Bienes Muebles, donde se van a ir alternando los contenidos; los que tienen un carácter científico específico bien teórico o experimental, los Proyectos, y la utilización de otras disciplinas aplicables al tratamiento del P.H, como los Sistemas de Información Geográfica o nuevas líneas en las que trabajar como las que abren las arqueología industrial o el turismo rural, tan de moda últimamente.

El orden que ocupan en el libro podríamos resumirlo en:

I) Una primera parte, que he denominado teórica, en la que autores y autoras reflexionan respecto a que es el patrimonio en cada uno de los campos en que trabajan, (arquitectónico, arqueológico, etnologico, bienes muebles) planteando en algunos casos modelos de estudio. Voy a centrarme en esta reseña en esta primera parte, y pasaré más ligeramente por las otras tres, ya que son experiencias más puntuales.

Se inicia con el Patrimonio arquitectónico y un sugerente subtítulo, Lo que el viento no se llevó, en el que Antoní Gonzalez tras su definición acerca de lo que él entiende por Patrimonio, donde aparecen términos como arquitectura del pasado reciente o lejano, consolidación y transmisión de identidades culturales y memorias colectivas, o transmisión entre generaciones etc., ve como chocan con la propia evolución a la que han llegado esas generaciones, los cambios de mentalidad, donde como él dice al menos en las sociedades occidentales se ha entrado en una acelerada y profunda crisis y transformación de los contenidos y programas de la arquitectura que han provocado la obsolescencia de gran parte de ese patrimonio poniendo en grave peligro su supervivencia. Si bien hay toda una serie de factores no controlables que conllevan a la desaparición de Patrimonio hay otros factores que si son controlables que los genera la propia sociedad, abandono, maltrato, desidia falta de recursos.... Es cierto que siempre acabamos utilizando estos términos, y también es cierto que hay a quien le generan problemas de conciencia, pero son tan pocas las conciencias afectadas.., tampoco

\footnotetext{
I Comunicación Oral de Concepción Barrero en las clases que impartió en el Curso "Patrimonio Histórico y Medio Rural, celebrado entre el 6 y el 17 de mayo de 1996 en La Universidad Internacional de Andalucía, Sede Antonio Machado, de Baeza (Jaén).

2 Tengo que decir, que a estas reflexiones han ayudado mucho la asistencia a algunos cursos que trataban sobre Patrimonio, como el que se ha mencionado anteriormente.
} 
vamos a rasgarnos aquí las vestiduras, porque es una situación que como bien se dice en el trabajo, es propia de los tiempos que nos toca vivir, y lo mismo que hay que extremar las medidas de protección de nuestro patrimonio también hay que exigir el máximo rigor en su definición y en su valoración, y esto es aplicable a todo el Patrimonio no únicamente al arquitectónico. $Y$ es precisamente en esos campos donde se desarrollará este articulo DEFINICION y VALORACION, para poder CATALOGAR y con ellos PROTEGER, reflexionando sobre cada uno de los términos y haciendo especial hincapié en la catalogación, que se entiende por catalogar patrimonio arquitectónico, y que tipo de catalogaciones se pueden llevar a cabo.

Para el Patrimonio arqueológico, Ruiz, Hornos y yo misma, partimos de la Historia de la arqueología y el desarrollo que ha tenido esta disciplina hasta llegar a la actualidad, se muestra el recorrido seguido desde la Arqueología del objeto a la recuperación del espacio y con ello a lo que se define como el Paradigma Contextual; esto nos lleva a plantear un nuevo discurso para explicar la naturaleza y los valores de la materia prima arqueológica retomando las cuatro funciones que Godelier exponía en su libro "Lo ideal y lo material", esto es: identificar, interpretar, organizar y legitimar, aplicándolas al proceso de trabajo arqueológico, lo que nos lleva a afrontar las tareas de catalogación del Patrimonio Arqueológico mediante el análisis de nuevas formas de apropiación, que se define en el trabajo como apropiación abstacta y apropiación concreta. Esto conduce en una primera aproximación a la catalogación a hablar de: I) La prospección arqueológica y los inventarios: la catalogación para la identificación; 2) Los estudios del territorio y la interpretación: La catalogación para la caracterización; 3) La función organizadora de la investigación para los programas de catalogación. Se definen tres unidades de trabajo en la catalogación arqueológica: Espacio arqueológico inventariado ( sin valor histórico y funcional y por lo tanto sin capacidad de interpretación en si mismo), el Territorio local, que asocia diferentes espacios arqueológicos identificados en el marco de la evolución, las funciones y las relaciones sociales que produce una comunidad local y el Territorio político, que se define por la articulación de una o varias comunidades locales en un espacio definido y controlado por un poder centralizado.

En una segunda aproximación a la catalogación, Investigar para proteger, proteger para conocer, se va a reflexionar sobre los diversos instrumentos legales de protección que tenemos hoy en la Comunidad Autónoma de Andalucía, tanto en el ámbito de la legislación urbanística (donde ya hemos visto antes la importancia de la figura de Planeamiento), como en el ámbito de la legislación de Patrimonio Histórico, correlacionándolo en la investigación con las unidades de trabajo que antes se planteaban.

Para los Bienes Muebles, Alfredo J. Morales, nos va a hacer un recorrido de como se ha contemplado y se contempla en la actualidad, la catalogación de los bienes muebles dentro de la evolución que ha tenido la legislación de Patrimonio Histórico, desde el siglo pasado, remontándose a algunos de los primeros decretos en el s. XVIII hasta llegar a la ley de Patrimonio Histórico Español de 25 de Junio de 1985, sin entrar en las legislaciones que se han vendido sucediendo en las distintas Comunidades. Muy brevemente señala al final que la incorporación de nuevas técnicas y herramientas como la informática, junto con una nueva concepción del Patrimonio Histórico, la que vengo comentando en los anteriores artículos, han abierto una nueva etapa en la Catalogación del Patrimonio Hstórico español que esta empezando a dar sus primeros frutos, sin entrar en un comentario a cerca del tema.

El último trabajo de esta primera parte, hace referencia al patrimonio etnológico "Los inventarios, herramienta de creación del Patrimonio Etnológico", en él, Francesc Llop i Bayó trata de plantearnos los problemas que surgen a la hora de trabajar con el Patrimonio etnológico, ya que la misma definición del término es tarea difícil. No se trata de un campo bien delimitado como pueden ser los que he tratado hasta ahora, aquí se van a entremezclar edificios, objetos, actividades muy distintas etc, que solo pueden comprenderse y asimilarse como elementos propios de una historia e identidad local. Parte de la definición de conceptos tales como Inventario, (sistemas de identificación, descripción y localización), de ahí que los defina como herramientas de gestión y difusión, catálogo, ( cuyo contexto es la ciencia "pura", la investigación académica, en torno a una serie corta de objetos ya conocidos y protegidos por los inventarios), por lo que lo define como un instrumento para el conocimiento; Patrimonio y Patrimonio etnológico, definiéndolo como un Patrimonio cambiante, mutable y variable en su coherencia, es un Patrimonio que cambiará con el tiempo y con las necesidades del grupo que lo sustenta, solo será patrimonio lo que la comunidad considere patrimonio. Ello le lleva a hablarnos de Patrimonio etnológico rural, P. etnológico urbano y P. etnológico industrial, con las dudas y enfrentamientos teoricos que han ocasionado en el ámbito de la investigación, sobre todo este último al chocar con la llamada Arqueología industrial. ¿Como inventariar pues este Patrimonio? pues partiendo de unos criterios de selección, unos criterios de protección y unos criterios de difusión. Precisamente este último le lleva a plantearnos el hasta ahora binómio patrimonio etnológico - museo etnológico, ya que esta parece ser la única forma de difusión para este patrimonio. Sin embargo él lo custiona, ya que la mayor parte de estos museos se encuentran bastante lejos del papel ideal de conservar, investigar, divulgar y educar. Por eso la conservación de éste patrimonio no debe restringirse a los museos, más bien deberian ser el último lugar, pero la ausencia de otros medios justifican su existencia como mal menor. Hay que ir hacia la creación de una conciéncia del Patrimonio etnológico, para que como los demás aspectos patrimoniales éste llegue a formar parte de la identidad colectiva y sea defendido como cosa propia.

2) Una segunda parte donde encontramos aquellos artículos que muestran experiencias de estos cuatro campos en Andalucía, partiendo de un primer trabajo, que nos expone en que consiste el Sistema de Información 
del Patrimonio Histórico de Andalucía SIPHA y las experiencias realizadas en este Centro de Documentación del P.H. creado por la administración andaluza, expuesto por $M^{a}$ del Carmen Ladron de Guevara, los cuatro siguientes nos hablan de experiencias que se han puesto en marcha para el P. arquitectónico, arqueológico, Etnológico, y por lo que respecta a los Bienes Muebles se presenta un artículo sobre La informatización de los repertorios documentales en museos, donde se explica el Programa Odiseus, por Antonio Limón.

3) Esta tercera parte nos muestra experiencias en distintos campos en otras comunidades Autónomas y otros paises. Para Cataluña Rosa Ma. Montserrat presenta "DAC: Documentación asistida de colecciones. Sistema integrado de Gestión de las colecciones de los Museos de Cataluña", para Valencia Antonio Cruces Rodríguez expone "XIPNET. Un proyecto integral de red informática distribuida para la difusión del Patrimonio Cultural y artístico de la Comunidad Valenciana", junto con "El Sistema Valenciano de inventarios y su plan de difusión telemática: XIPWAY". Como experiencias en otros países, Jöel Perrin y Philippe Araguas, escriben sobre el Inventario del Patrimonio Histórico en Francia, planteando de una forma bastante general como funciona el sistema en el País vecino.
4) En la parte final tal y como he visto la estructura de esta obra, irían, toda una serie de artículos donde vemos la aplicación de nuevas disciplinas al tratamiento del Patrimonio Histórico y las nuevas líneas en las que se viene trabajando. Fernando Giménez de Azcarate Fernández, presenta EI SINANBA como ejemplo de los Sistemas de Información Geográfica aplicadas al Patrimonio, Xavier Costa El Proyecto DOCOMOMO, Juan Carlos Jiménez Barrientos, el Panorama actual del Inventario industrial Andaluz, y como muy bien él subtitula, Proyectos e intenciones, Horacio Capel nos habla sobre El turismo industrial y el Patrimonio Histórico de la electricidad y para acabar Salvador Rodríguez Becerra plantea algunas cuestiones sobre La problemática en torno a la catalogación de la arquitectura tradicional.

No creo que sea oportuno entrar a tratar detalladamente cada uno de esos artículos ya que trascendería a lo que pretendia ser esta reseña. Quizás sea mejor dejarlo así instando a otros posibles lectores y lectoras de esta obra, y esperando que la lectura de ésta les suscite la reflexión. 